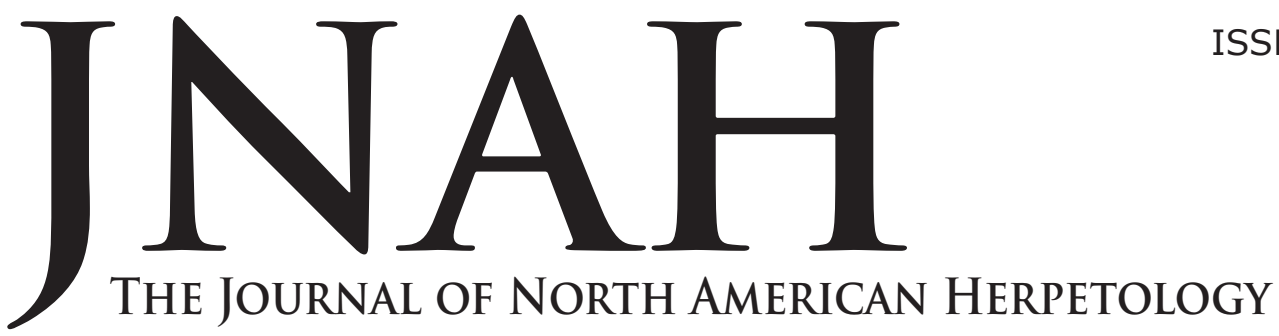

ISSN 2333-0694

Volume 2020, Number 1

23 March 2020

journals.ku.edu/jnah

\title{
MORPHOLOGY, REPRODUCTION, SEASONAL ACTIVITY AND HABITAT USE OF A NORTHERN POPULATION OF THE SMOOTH GREENSNAKE (OPHEODRYS VERNALIS)
}

\author{
PAMELA L. RUTHERFORD., ${ }^{1,3}$ AND NICHOLAS A. CAIRNS ${ }^{1,2}$ \\ ${ }^{1}$ Department of Biology, Brandon University, Brandon, Manitoba R7A 6A9, Canada \\ 2Present address: Department of Biology, Queen's University Biosciences \\ Complex, 116 Barrie St., Kingston, ON, Canada K7L 3N6 \\ ${ }^{3}$ Correspondence: email, rutherfordp@brandonu.ca
}

\begin{abstract}
The Smooth Greensnake (Opheodrys vernalis) is a small, slender, oviparous, colubrid snake that is widely distributed in North America. Nonetheless, there have been few studies on this species, and little is known about Canadian populations. The objective of this study was to examine morphology, reproduction, seasonal activity and habitat use of a northern population of the Smooth Greensnake. Individuals were captured during the summers of 2007-2010 in southwestern Manitoba, Canada. Females were larger and relatively heavier than males, but clutch size did not consistently increase with body size. In addition, 59\% (on average) of available adult females were gravid in any given year, suggesting that females may not reproduce each year. Males had relatively longer heads and longer tails than females. Males were more common in early August; otherwise, females were more common. The peak of male activity in August suggests that fall mating might occur in this species, but this was not confirmed. Finally, Smooth Greensnakes were most commonly found in grassland, and there were no differences in habitat use between the sexes. Further research on northern populations of Smooth Greensnakes would provide valuable information on this little-studied species.
\end{abstract}

Key Words: cool-climate; Manitoba; Opheodrys vernalis; sexual size dimorphism

INTRODUCTION

Body sizes frequently differ between males and females among many taxa (Fairbairn et al., 2007). In reptiles, larger body size in females is common (Shine, 1993) and this is often attributed to the positive relationship between body size and fecundity (Shine, 1988; Reeve and Fairbairn, 1999). Other morphometric traits (e.g. tail length, head size) differentially scale with body size. For example, male snakes typically have relatively longer tails to provide space for hemipenes (Shine, 1999). In snakes, differences in head sizes have been attributed to prey differences (Slatkin, 1984; Houston and Shine, 1993), but species vary in whether females or males have relatively larger head sizes (King et al., 1999). In contrast to snakes, some territorial lizards show an increase in sexual dimorphism in head sizes with ontogeny (King et al., 1999). This reflects sexual selection for increased head size in males and natural selection for increased body size (and fecundity) in females.

Reproductive requirements of females also contribute to sex differences in habitat use and temperature selection in reptiles. Thermal requirements of developing em- bryos may cause females to select different habitats than males and alter their thermoregulatory behavior (Shine et al., 2006). This has been shown for both viviparous and oviparous species, particularly those with significant egg retention during gestation (Rodríguez- Díaz et al., 2010). In squamates, gravid females may select warmer or cooler temperatures depending on species and the environments in which they are found (Shine, 2006). The cold-climate hypothesis predicts that warmer temperatures will be selected by gravid female squamates in cold climates to ensure rapid embryo development (Tinkle and Gibbons, 1977). Alternatively, the maternal manipulation hypothesis predicts that gravid females will select temperatures that optimize offspring survivorship (Shine, 1995).

Sexual size dimorphism has been examined in numerous snake species (reviewed by Shine, 1994). In this project we examined morphology, reproduction, and habitat use of males and females in a northern population of the Smooth Greensnake (Opheodrys vernalis, formerly known as Liochlorophis vernalis). The Smooth Greensnake is a small, slender, oviparous, colubrid snake 
Table 1: Morphological measures and the number of captures (N) for each sex by year (2007-2010) and all years combined (Total), including both non-gravid and gravid females. Morphological measurements include: snout-vent length (SVL), tail length, head width, head length, and mass. Mean and standard error (SE) are reported for each morphological measure.

\begin{tabular}{lrrrrrrrrrr}
\hline & 2007 & & 2008 & & 2009 & & 2010 & Total \\
\hline \multirow{2}{*}{ SVL (mm } & $\mathrm{F}$ & $\mathrm{M}$ & $\mathrm{F}$ & $\mathrm{M}$ & $\mathrm{F}$ & $\mathrm{M}$ & $\mathrm{F}$ & $\mathrm{M}$ & $\mathrm{F}$ & $\mathrm{M}$ \\
& 248 & 225 & 246 & 209 & 236 & 198 & 236 & 198 & 241 & 205 \\
& $(8.9)$ & $(9.2)$ & $(5.0)$ & $(4.5)$ & $(4.8)$ & $(4.8)$ & $(9.1)$ & $(5.6)$ & $(3.0)$ & $(2.8)$ \\
\hline Tail Length (mm) & 94 & 105 & 92 & 98 & 87 & 102 & 87 & 99 & 90 & 100 \\
& $(3.6)$ & $(8.2)$ & $(2.0)$ & $(3.2)$ & $(2.1)$ & $(3.1)$ & $(3.3)$ & $(3.3)$ & $(1.3)$ & $(1.9)$ \\
\hline Head Width (mm) & 5.2 & 4.9 & 5.0 & 5.0 & 4.7 & 4.5 & 4.6 & 4.5 & 4.8 & 4.7 \\
& $(0.16)$ & $(0.20)$ & $(0.08)$ & $(0.09)$ & $(0.06)$ & $(0.09)$ & $(0.11)$ & $(0.09)$ & $(0.05)$ & $(0.06)$ \\
Head Length (mm) & $\mathrm{NA}$ & $\mathrm{NA}$ & 8.8 & 8.7 & 9.0 & 8.8 & 9.2 & 9.1 & 9.0 & 8.8 \\
& & & $(0.15)$ & $(0.15)$ & $(0.11)$ & $(0.15)$ & $(0.20)$ & $(0.14)$ & $(0.08)$ & $(0.09)$ \\
\hline Mass (g) & 10.0 & 5.7 & 8.7 & 5.6 & 8.7 & 5.3 & 8.2 & 5.3 & 8.8 & 5.5 \\
& $(0.77)$ & $(0.52)$ & $(0.43)$ & $(0.27)$ & $(0.45)$ & $(0.27)$ & $(0.77)$ & $(0.32)$ & $(0.27)$ & $(0.16)$ \\
\hline $\mathrm{N}$ & 18 & 8 & 53 & 50 & 57 & 38 & 15 & 19 & 143 & 115 \\
\hline
\end{tabular}

that is widely distributed in North America. They range from the Canadian Maritime Provinces and the Appalachian Mountains of Virginia to Saskatchewan, Utah and New Mexico, and isolated populations occur in Chihuahua (Mexico), and southeastern Texas (Conant and Collins, 1991; Grobman, 1992; Redder et al., 2006; Walley, 2003). There have been no studies that determine population trends, but some populations that were once widespread are now reduced and scattered (reviewed by Redder et al., 2006). In Canada, little is known about historical or current population sizes of this species, but their habitat is declining through conversion to agriculture, urbanization, and road construction (Samson et al., 2004). Typically, they inhabit thick grassy, herbaceous, and shrubby vegetation, and also can be found in wetlands, riparian areas, and along forest edges (Redder et al., 2006).Smooth Greensnakes are insectivorous, appearing to prefer noctuid moth larvae, but incorporating other prey species (e.g. spiders, harvestmen, crickets and slugs), depending on seasonal changes in availability (Waters, 1993). They are diurnal, surface-active snakes (Waters, 1993; Redder et al., 2006) that typically have relatively long tails (Shine and Wall, 2008). Little is known about reproductive cycles for either sex in Manitoba (Gregory, 1977), and observed sex ratios from field studies are female biased (Siebert and Hagen, 1947; Gregory, 1977). This species has been described as bordering on ovoviviparity because its eggs are often retained for extended periods and typically hatch more quickly than most oviparous snakes. In Manitoba, oviposition has been reported from late-June to mid-July (Gregory, 1977). The objective of this study was to examine morphology, reproduction, seasonal activity and habitat use of a northwestern population of the Smooth Greensnake (Opheodrys vernalis). Specifically, we asked the following four questions: 1) Do Smooth Greensnakes exhibit sexual dimorphism? 2) Do females vary among years in the percent that are reproductive and the numbers of follicles? 3) Do males and females have different seasonal activity patterns? 4) Do males and females use different habitats?

\section{MATERIALS AND METHODS}

This study took place in southwestern Manitoba, Canada at the following locations: Spruce Woods Provincial

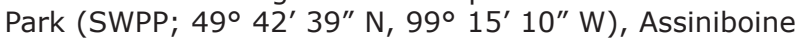
Corridor Wildlife Management Area (ACWMA; 49० 40' 03"

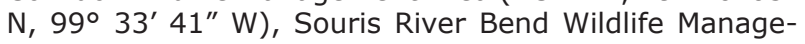

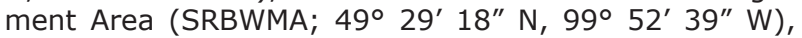
Oak Lake ( $\left.49^{\circ} 39^{\prime} 52^{\prime \prime} \mathrm{N}, 100^{\circ} 42^{\prime} 48^{\prime \prime}\right)$ and Canadian

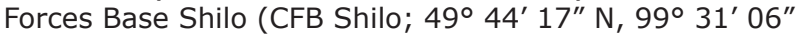
W). A wide variety of habitats were investigated from agricultural areas to beaver ponds; most sites incorporated water and/or prairie. Details on the habitat types are provided below.

Field sites were surveyed every 2-3 weeks in 20072010, from April to September of each year. Searching varied between morning and afternoon in order to compare daily habitat usage as the season progressed. We used the same investigatory walking path each time a site was visited in order to standardize search effort. These routes traveled around or through potentially suitable habitat, often following barriers such as creeks, park paths or tree lines. In more homogeneous landscapes, such as prairie, the same routes were walked on each visit. Animals were captured by hand as they moved in the open, or when located under cover objects, both natural and anthropomorphic (e.g. plywood, sheet metal). Anthropromorphic cover was distributed for a different study, and included a mix of cover boards (one foot by two foot $3 / 4$ inch plywood) and refuse that had been deposited by others in the area.

The following measurements were taken for all captured snakes: date, time, snout-vent length (SVL in $\mathrm{mm})$, tail length $(\mathrm{mm})$, head width $(\mathrm{mm})$, head length $(\mathrm{mm})$, mass $(\mathrm{g})$, sex, age class, and reproductive condition. To determine reproductive condition, two individuals independently counted enlarged ovarian follicles by palpation (Fitch, 1987) and the average of their counts was taken. All captured individuals $(n=272)$ were scaleclipped for future identification and released at their capture site within 15 minutes of capture. No snakes in this study received more than three clipped ventral scales.

Recaptures rates were low. Six snakes were captured twice $(2 \%)$, and five of these six snakes were recaptured 
Table 2: Comparisons among numbers of gravid females, numbers of follicles per gravid female, and numbers of young-of-theyear over four years (2007-2010).

\begin{tabular}{|c|c|c|c|c|c|}
\hline & 2007 & 2008 & 2009 & 2010 & Total \\
\hline $\begin{array}{l}\text { Number } \\
\text { of Gravid } \\
\text { females } \\
\text { (\% gravid) }\end{array}$ & $6(55 \%)$ & $26(76 \%)$ & $17(47 \%)$ & $5(50 \%)$ & $54(59 \%)$ \\
\hline $\begin{array}{l}\text { Follicles } \\
\text { (Mean } \pm \\
\text { SE) }\end{array}$ & $8.2 \pm 1.17$ & $4.3 \pm 0.24$ & $5.4 \pm 0.36$ & $3.0 \pm 0$ & $5.1 \pm 0.70$ \\
\hline $\begin{array}{l}\text { Numbers } \\
\text { of YOY }\end{array}$ & 0 & 15 & 14 & 3 & 32 \\
\hline
\end{tabular}

within the same year. Two snakes were captured four times $(1 \%)$. Only a single capture per year (per individual) was included in the analyses. Females with SVLS larger than $225 \mathrm{~mm}$ (minimum SVL of all gravid females) were classified as adults; otherwise, they were classified as juveniles. Minimum breeding size is not known for males. For both sexes, the juvenile class also includes young-of-the-year (YOY). The activity period (May 10 to September 9) also classified by weeks 1 through 18, and this variable was considered a categorical variable in all analyses.

At the site of capture we recorded the following environmental and location data: UTM location, aspect (from
0 - 35), and local dominant vegetation. Absolute (UTM coordinates) location information was recorded using a Garmin $®$ GPS60 handheld GPS receiver (WAAS enabled accuracy: < $3 \mathrm{~m}, 95 \%$ typical). Global Positioning Systems (GPS) data were used to classify the capture locations according to land cover classes defined by the Manitoba Land Initiative (URL:https:// mli2.gov.mb.ca//. Accessed: 2012-02-025 Archived by WebCite ${ }^{\circ}$ at http:// www.webcitation.org/659exUaEF). The following eight classes were used: Agriculture, Bogs, Conifer Forest, Deciduous Forest, Grassland, Grassland/Deciduous Forest, Grassland/Roads, and Roads/Trails. Assignments were made using ArcGIS ver. 10 (Esri, 2011)(ESRI, Redlands, CA).

All data analyses were done in R 3.4 (R Core Team, 2017) and $a=0.05$ was used to assess significance. We report means and standard errors where applicable. Data were log-transformed or nonparametric tests were used when assumptions of parametric tests were not satisfied. Unless otherwise indicated adult females include both gravid and nongravid individuals. T-tests were used to compare SVLs of all males and females, and to compare the SVLs of gravid and nongravid females. Linear regression was used to determine if aspect of the capture location changed over the season. ANCOVAs were used to compare tail length, head width, head length, and log-transformed mass of males and females using SVL as the covariate. ANCOVA was used to compare the number
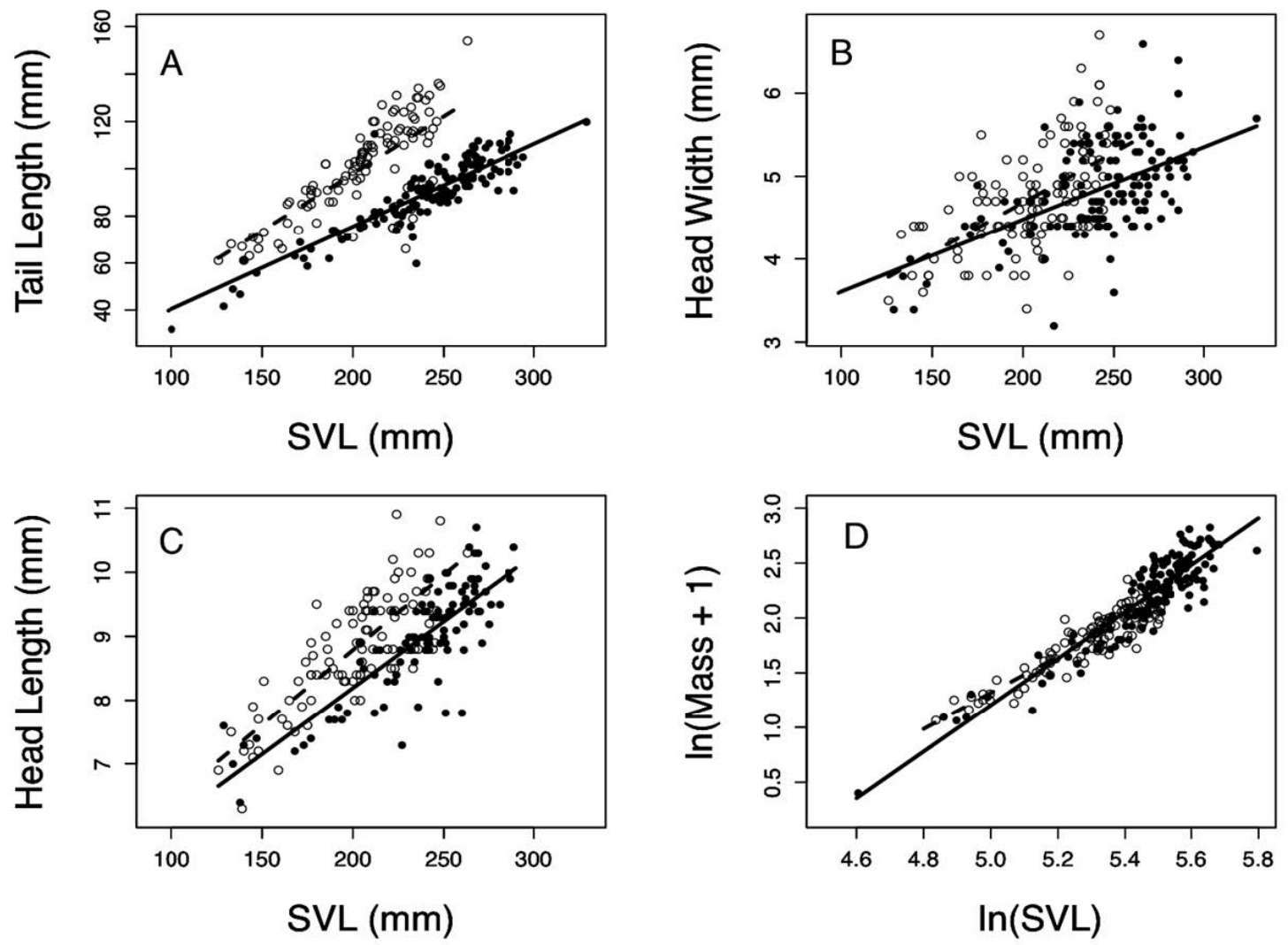

Figure 1. A) Tail length $(\mathrm{mm})$, B) head width $(\mathrm{mm}), \mathrm{C})$ head length $(\mathrm{mm})$, and D) log-transformed (mass +1 ) versus snout-vent length (SVL in $\mathrm{mm}$ ) for male (open circles and dashed lines) and female (closed circles and solid lines) Smooth Greensnakes. Least squares regression lines indicate significant relationships between variables within each sex. Tail length $(A)$ increased significantly faster with SVL in males compared to females, while mass (D) increased significantly faster with SVL in females compared to males. There was no difference in the relationship between SVL and head width (B), or SVL and head length (C) in males and females, but males had relatively longer heads than females (C). 
of follicles in gravid females among three years (20072009; 2010 was excluded in this analysis because number of follicles was only counted by a single individual) using SVL as a covariate. In all models, interaction terms were evaluated and removed when not significant. Main effects were reported only after removal of the non-significant interaction terms from the model. Chi-square analyses were used to compare the following: numbers of gravid females captured over the four years, numbers of YOY captured over four years, numbers of males and females captured, and numbers of males and females captured in the open versus under cover, and numbers of gravid versus nongravid adult females captured in the open versus under cover. We used a Log-likelihood ratio (G-test) test of independence without correction to compare numbers of captures and land use patterns over the 18 week season, and to compare land-cover use among sexes.

\section{RESULTS}

Morphology - Females had significantly longer SVLS than males $(t=8.8, d f=255.8, p<0.001$; Table 1$)$. Tail length increased significantly more with SVL in male Smooth Greensnakes than in females $(F[1,250]=12.30$, $p<0.001$; Figure $1 \mathrm{~A})$. Neither head width $(F[1,252]=$ $2.70, p=0.10)$ nor head length $(F[1,252]=1.40, p=$ 0.24 ) differed in their relationship with SVL for males compared to females, therefore the interactions terms were removed from the models. When we evaluated only the main effects, there was no difference between head widths of males and females $(F[1,253]=2.99, p$ $=0.08$; Figure $1 \mathrm{~B}$ ), but males had significantly longer heads than females when we controlled for body size $(F[1,200]=4.37, p=0.04$; Figure $1 C)$. Log-transformed mass increased significantly more with log-transformed SVL among females (not including gravid females) than males $(F[1,195]=17.63, p<0.001$; Figure 1D).

Reproduction - Gravid females were captured from May 22 to August 2 (Figure 2). More than half of the adult female Smooth Greensnakes (59\%, $n=54$ ) captured during this time period were gravid. The numbers of gravid versus nongravid adult females captured during this time period did not significantly differ between the four years ( $\mathrm{X} 2=6.79, \mathrm{df}=3, p=0.08)$, although there tended to be a higher percentage in 2008 (Table 2). Finally, there was no significant difference in SVL of gravid adult females compared to nongravid adult females ( $t=$ 1.05, $d f=80.7, p=0.30$ ).

Gravid females had a mean of $5.1 \pm 0.70$ follicles (range: 2 - 12; Table 2). There was a significant difference in the relationship between SVL of gravid females and their number of follicles among the three years $(F[2,31]=5.51, p=0.009)$. In both 2007 and 2009,
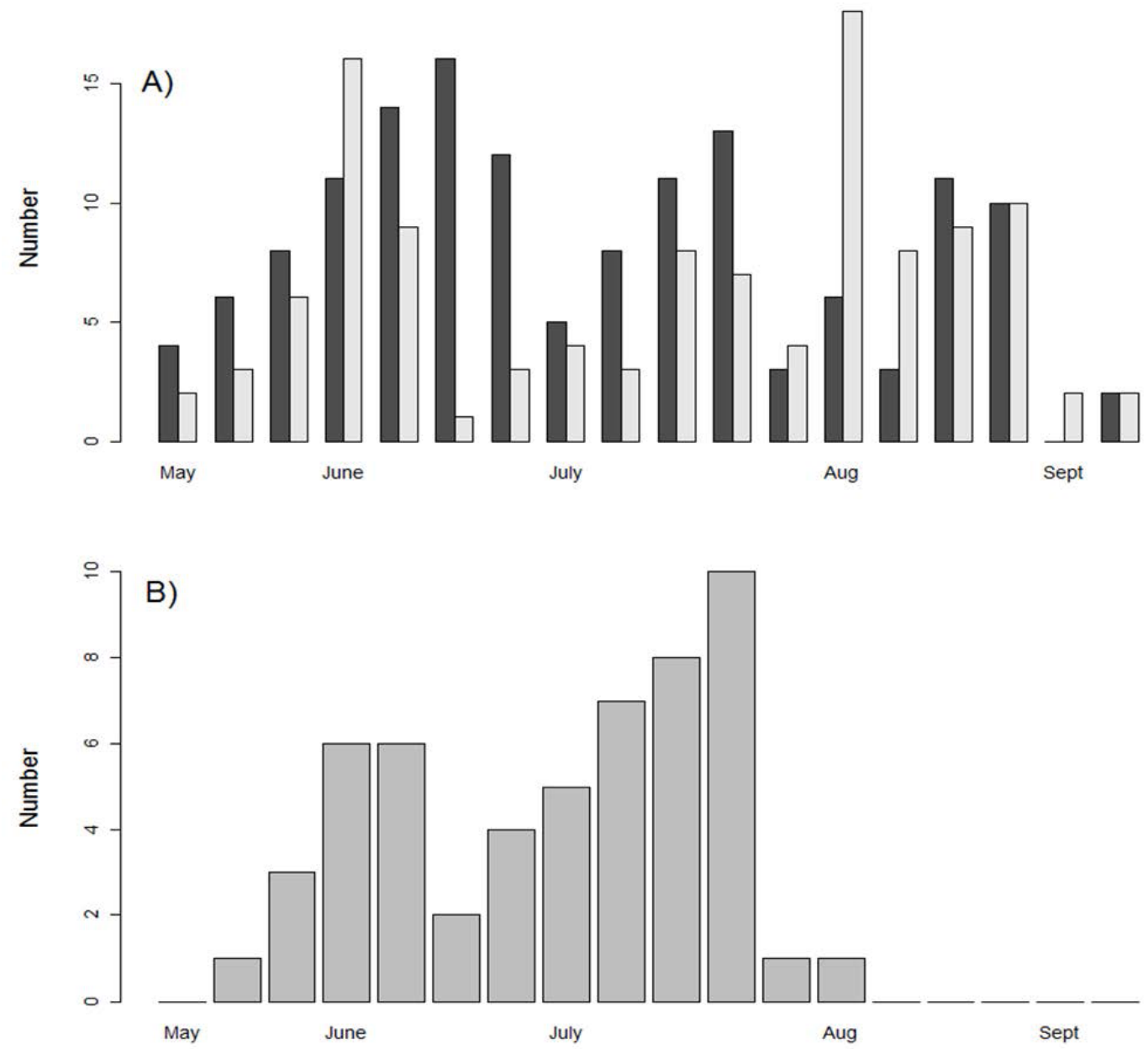

Figure 2. Numbers of captures of A) female (black bars) and male (grey bars), and B) gravid female Smooth Greensnakes over the 18 week season from May 10 to September 9 over four years (2007-2010). 
there was no significant relationship between SVL and the number of follicles (2007: $(F[1,3]=3.13, p=0.18$; 2009: $(F[1,9]=0.13, p=0.72)$, but the number of follicles increased with SVL in $2008(F[1,19]=7.12, p=$ 0.02 ). The number of follicles significantly varied among the three years $(F[2,31]=15.7, p<0.001$; Table 2$)$ with 2007 having the largest mean number of follicles and 2008 the least mean number of follicles.

Young-of-the-year (YOY) juveniles were captured from August 4 to September 9. There was a significant difference in the numbers of YOY captured over the four years, with the most captured in 2008 and 2009, and the least in 2007 (X2 = 21.75, $d f=3, p<0.001$; Table 2). Mean SVL of YOY was $142.4 \pm 4.2 \mathrm{~mm}$ (range: $88-180 \mathrm{~mm}$ ) and mean mass was $2.3 \pm 0.1 \mathrm{~g}$ (range: $0.7-4.1 \mathrm{~g}$ ). We were unable to determine sex for $41 \%$ of theYOY ( $n=$ 13). Of those where sex was determined, moremale YOY $(68 \%, n=13)$ were captured than female YOY $(32 \%, n$ $=6)$.

Seasonal Activity - There tended to be more females captured than males (female: $n=143$, male: $n=115$; $\mathrm{X} 2=3.04, d f=1, p=0.08$; Table 1 ). Sex ratios significantly varied across the 18 weeks $(G=39.23, d f=17$, $p=0.002$, Figure $2 A$ ), and the number of gravid females captured varied significantly across the 18 weeks ( $G=$ 67.47, $d f=17, p<0.001$, Figure 2B). Male Smooth Greensnakes were equally or more frequently encountered in the first week of June, and the first and second weeks of August; otherwise, adult females were more frequently or equally encountered. Gravid females were captured most frequently in mid- to late-July.

Habitat Use - Smooth Greensnakes were most frequently found in grassland $(71 \%, n=201)$; the remaining $29 \%$ of captures were distributed among: deciduous forest $(16 \%, n=46)$, roads/trails $(8 \%, n=23)$, and all other habitat types $(4 \%, n=12)$. Land cover use did not differ for Smooth Greensnakes over the season ( $G$ $=113.63, d f=119, p=0.62$ ). There was no difference in land cover use among adults, juveniles and YOY ( $G=$ $13.46, d f=14, p=0.49$ ). Also, there was no difference in land cover use between adult males and females, or juvenile males and females $(G=5.54, d f=7, p=0.59$ and $G=11.17, d f=7, p=0.13$ ). Finally, there was no difference in land cover use by gravid versus nongravid females $(G=10.56, d f=7, p=0.16)$.

Dominant grassland vegetation included: Leafy Spurge (Euphorbia esula, 19\%), June Grass (Koeleria cristata, $18 \%)$, Sedge (Carex spp., 13\%), Creeping Juniper (Juniperus horizontalis, $11 \%$ ), and Smooth Brome (Bromus inermis, 8\%). Similar local dominant vegetation was found in the deciduous forest habitat: Leafy Spurge (Euphorbia esula, 26\%), Creeping Juniper (Juniperus horizontalis, 26\%), June Grass (Koeleria cristata, 16\%), and Sedge (Carex spp., 7\%).

Most captures were on flat ground ( $55 \%, n=137)$. Individuals were captured on slopes that had a mean aspect of $11.3 \pm 0.5$ (southeast facing). Aspect declined over the season $(F[1,109]=8.92, P=0.003)$ from means of $12.0 \pm 1.7$ in May (southeast facing) to $8.5 \pm$ 0.5 in September (east facing).

Most captures were under cover $(92 \%, n=232)$, and females tended to be found more in the open than males (females: $11 \%, n=16$; males: $4 \%, n=5 ; \times 2=3.03$, $\mathrm{df}=1, p=0.08)$. There was no significant difference in the percent of gravid versus nongravid adult females that were found in the open (gravid: $15 \%, n=8$; nongravid: $9 \%, n=5 ; \times 2=0.31, d f=1, p=0.58)$. Cover types used by all individuals were: plywood $(84 \%, n=210)$, particleboard (4\%, $n=11)$, and all other $(13 \%, n=32)$. Mean cover thickness was $22.1 \pm 1.7 \mathrm{~mm}$ (range: 1 $280 \mathrm{~mm}$ ). These numbers may reflect the percentages of available cover and not preferences, as there was no systematic analysis of cover availability and preference conducted in this study.

\section{DISCUSSION}

Smooth Greensnakes exhibited sexual size dimorphism; females were larger (both SVL and relative mass) than males, and males had relatively longer tails and heads for their body size than females. In other species, larger female body size is a consequence of the positive relationship between body size and clutch size (Seigel and Ford, 1987). In our study, clutch size was only positively related to body size in one year of the study. This does not mean that sexual size dimorphism is not a consequence of selective pressures for increases in reproductive output, but suggests that other factors are also affecting reproductive output. Perhaps smaller clutches had larger egg sizes; this tradeoff results in larger body sizes at hatching thus improving survival chances for the young (Sinervo, 1999). Alternatively, the timing of delayed oviposition significantly affects reproductive output in this species (Gregory, 1977). Gravid females were detected as late as early August in this population and young-of-the-year were captured around the same time, indicating significant delays in egg laying. The timing of oviposition appears plastic in other northern populations of this species, ranging from 4 days (Blanchard, 1933) up to 30 days (Messmer et al., 1995). In addition, 59\% (on average) of available adult females were gravid in any given year suggesting that individuals may not reproduce each year. There was no significant difference in SVL of gravid versus nongravid females. Further research is required to understand the interaction between reproductive skipping, delayed oviposition, and female body size on reproductive output in this species.

Tail length increased faster with SVL in males than females, which is consistent with sexual selection for tail length (Shine, 1999). Males also had relatively longer heads, but this relationship was similarly evident in juveniles and adults. This suggests that sex differences in head sizes were not related to sexual selection, although little is known about mating behavior in this species. Other species exhibit head size differences related to diet (Slatkin, 1984; Houston and Shine, 1993). Males and females inhabited the same habitat types, although this does not preclude selection of different types and sizes of prey (Pianka, 1969). Enlarged male head sizes in our population are consistent with a response to a decrease in intersexual competition for resources, and not consistent with increased energetic requirements of females associated with reproduction (Slatkin, 1984; Hedrick and Témeles, 1989), but further data on dietary preferences are required to confirm this hypothesis.

Sex differences in seasonal activity of adults are likely related to reproduction. Males were most prevalent in early August, which had been suggested as the mating season for Manitoba populations (Gregory, 1977). Our data are consistent with this hypothesis, but we were not able to confirm that mating occurs in the fall. Fall mating is a reproductive behavior that has been suggested for viviparous species in northern climes (Willson and Dorcas, 2004), but not in any oviparous species. Throughout the remainder of the summer, females were more likely 
to be captured which is consistent with other northern populations of Smooth Greensnakes (Siebert and Hagen, 1947; Gregory, 1977). Females may be generally more active (and more likely to be captured) during the summer due to high energetic requirements associated with reproduction in northern climates (Gregory, 2009). This will be true for gravid females, but also nongravid females, who must attain a condition threshold for reproduction in future years. These patterns are typically seen in viviparous species (Gregory, 2009), and although this species is oviparous, the significant delays in egg laying may result in reproductive behavior more akin to viviparous squamate species. By retaining eggs for a longer period, females may be able use thermoregulatory behavior to increase incubation temperatures and provide less variable incubation temperatures (Charland and Gregory, 1990; Charland, 1995; Crane and Greene, 2008). This thermoregulatory behavior will result in faster embryonic growth rates and ultimately decrease incubation times, and will result in more viable offspring (Beuchat, 1988; Shine and Harlow, 1993; Lourdais et al., 2004). In conclusion, the objective of this study was to examine morphology, reproduction, seasonal activity and habitat use of a northern population of the Smooth Greensnake (Opheodrys vernalis). We found that females were larger than males, but clutch size only increased with female body size in one of the three years, suggesting other factors contribute to reproductive output of females. Males had relatively longer head sizes (as both juveniles and adults) suggesting diet differences, and not sexual selection, as a driving selective force. Males were more common in early August suggesting that there is fall mating for this population; otherwise, females were more common. Finally, Smooth Greensnakes were most commonly found in grassland, and there were no differences in habitat use between the sexes. Further research on northern populations of Smooth Greensnakes would provide a unique opportunity to explore hypotheses about factors producing sex differences in squamates, and provide valuable information on this little-studied species.

Acknowledgments - Thanks to L. Cairns, R. Cairns, B. Cairns, J. Cairns, R. Dale, T. Dempsey, A. Dransfield, N. Gushulak, C. Jaeger, J. Larkin, D. Macintyre and J. Phillips for their assistance in the field and study design. Ella May-Stewart Perdue Trust Fund, Brandon University Research Committee, Brandon University Student Union Fellowship and Department of Zoology provided financial support. All protocols were done with the approval of the Brandon University Animal Care Committee (2011 R07) and all necessary permits for field study were obtained. We also thank anonymous reviewers for their valuable feedback.

\section{LITERATURE CITED}

Beuchat, C.A. 1988. Temperature effects during gestation in a viviparous lizard. Journal of Thermal Biology 13: 135-142.Blanchard, F.N. 1933. Eggs and young of the smooth green snake, Liopeltis vernalis (Harlan). Papers of the Michigan Academy of Science, Arts and Letters 17: 493-514.

Charland, M.B. 1995. Thermal consequences of reptilian viviparity: Thermoregulation in gravid and nongravid Garter Snakes (Thamnophis). 9: 383-390.

Charland, M.B., and P.T. Gregory. 1990. The influence of female reproductive status on thermoregulation in a viviparous snake, Crotalus viridis. Copeia 1990: 10891098.

Conant, R., and J.T. Collins. 1991. A Field Guide to Amphibians and Reptiles of Eastern and Central North America. 3rd ed. Houghton Mifflin Company, Boston, Massachusetts, USA.

Crane, A.L., and B.D. Greene. 2008. The effect of reproductive condition on thermoregulation in female Agkistrodon piscivorus near the Northwestern range limit. Herpetologica 64: 156-167.

ESRI R. 2011. ArcGIS desktop: Release 10. Environmental Systems Research Institute, CA

Fairbairn, D.J., W.U. Blanckenhorn, and T. Szekely. 2007. Sex, Size and Gender Roles: Evolutionary Studies of Sexual Size Dimorphism. Oxford University Press, New York.

Fitch, H.S. 1987. Collecting and life-history techniques. Pp. 143-164 In: Seigel, R.A., Collins, J.T., and Novak, S.S. (Eds.). Snakes: Ecology and Evolutionary Biology. Macmillan, New York, USA.

Gregory, P.T. 1977. Life history observations of three species of snakes in Manitoba. Canadian Field Naturalist 91: 1-9.

Gregory, P.T. 2009. Northern lights and seasonal sex: The reproductive ecology of cool-climate snakes. Herpetologica 65: 1-13.

Grobman, A. 1992. On races, clines, and common names in Opheodrys. Herpetological Review 23: 14-15.

Hedrick, A.V., and E.J. Témeles. 1989. The evolution of sexual dimorphism in animals: hypotheses and tests. Trends in Ecology \& Evolution 4: 136-138.

Houston, D., and R. Shine. 1993. Sexual dimorphism and niche divergence : Feeding habits of the Arafura Filesnake. Journal of Animal Ecology 62: 737-748.

King, R.B., T.D. Bittner, A. Queral Regil, and J.H. Cline. 1999. Sexual dimorphism in neonate and adult snakes. Journal of Zoology 247: 19-28.

Lourdais, O., R. Shine, X. Bonnet, M. Guillon, and G. Naulleau. 2004. Climate affects embryonic development in a viviparous snake, Vipera aspis. Oikos 104: 551-560.

Messmer, T.A., F.B. Lee, and T. Rich. 1995. Smooth green snake (Opheodrys vernalis). North Dakota State University Extension Service

Pianka, E.R. 1969. Sympatry of desert lizards (Ctenotus) in Western Australia. Ecology 50: 1012-1030.

R Core Team. 2017. R: A language and environment for statistical computing. R Foundation for Statistical Computing, Vienna, Austria.

Redder, A.J., B.E. Smith, and D.A. Keinath. 2006. Smooth Green Snake (Opheodrys vernalis): A technical conservation assessment. USDA Forest Service, Rocky Mountain Region.

Reeve, J.P., and D.J. Fairbairn. 1999. Change in seuxal size dimorphism as a correlated response to selection on fecundity. Heredity 83: 697-706.

Rodríguez-Díaz, T., F. González, X. Ji, and F. Braña. 2010. Effects of incubation temperature on hatchling phenotypes in an oviparous lizard with prolonged egg retention are the two main hypotheses on the evolution of viviparity compatible? Zoology 113: 33-38.

Samson, F.B., F.L. Knopf, and W.R. Ostlie. 2004. Great Plains ecosystems: past, present, and future. Wildlife Society Bulletin 32: 6-15.

Seigel, R.A., and N.B. Ford. 1987. Reproductive Ecology. Pp. 210-252 In: Collins, J.T., and Novack, S.S. (Eds.). 
Snakes: Ecology and Evolutionary biology. Macmillan, New York, USA.

Shine, R. 1988. The evolution of large body size in females: a critique of Darwin's "fecundity advantage" model. American Naturalist 131: 124-131.

Shine, R. 1993. Sexual dimorphism in snakes. Pp. 49-86 In: Collins, J.T. (Ed.). Snakes: Ecology and Behavior. McGraw Hill, New York, USA.

Shine, R. 1994. Sexual size dimorphism in snakes revisited. Copeia 1994: 326-346.

Shine, R. 1995. A new hypothesis for the evolution of viviparity in reptiles. American Naturalist 809-823.

Shine, R. 1999. Why do male snakes have longer tails than females? Proceedings of the Royal Society of London. Series B: Biological Sciences 266: 2147-2151.

Shine, R. 2006. Is increased maternal basking an adaptation or a pre-adaptation to viviparity in lizards? Journal of Experimental Zoology. Part A, Ecological Genetics and Physiology 305A: 524-535.

Shine, R., and P. Harlow. 1993. Maternal thermoregulation influences offspring viability in a viviparous lizard. Oecologia 96: 122-127.

Shine, R., and M. Wall. 2008. Interactions between locomotion, feeding, and bodily elongation during the evolution of snakes. Biological Journal of the Linnean Society 95: 293-304.
Shine, R., J. Webb, A. Lane, and R. Mason. 2006. Flexible mate choice: a male snake's preference for larger females is modified by the sizes of females encountered. Animal Behaviour 71: 203-209.

Siebert, H.C., and C.W. Hagen. 1947. Studies on a population of snakes in Illinois. Copeia 1947: 6-22.

Sinervo, B. 1999. Mechanistic analysis of natural selection and a refinement of Lack's and Williams' principles. American Naturalist 154: S26-S42.

Slatkin, M. 1984. Ecological causes of sexual dimorphism. Evolution 38: 622-630.

Tinkle, D.W., and J.W. Gibbons. 1977. The distribution and evolution of viviparity in reptiles. Miscellaneous Publications, Museum of Zoology, University of Michigan 154: 1-55.

Walley, H.D. 2003. Liochlorophis vernalis. Catalogue of American Amphibians and Reptiles 776: 1-13.

Waters, R.M. 1993. Seasonal prey preference by the Smooth Green Snake. Central Michigan University, Mount Pleasant, Michigan, USA.

Willson, J.D., and M.E. Dorcas. 2004. Aspects of the ecology of small fossorial snakes in the western Piedmont of North Carolina. 